\title{
Reconstructing Our Ships: Navigating the Use of Simulation in CSD
}

Carol C. Dudding

James Madison University, duddincc@jmu.edu

DOI: https://doi.org/10.30707/TLCSD4.3/JNXD4642

Follow this and additional works at: https://ir.library.illinoisstate.edu/tlcsd

Part of the Curriculum and Instruction Commons, Educational Technology Commons, and the Higher Education Administration Commons

\section{Recommended Citation}

Dudding, Carol C. (2020) "Reconstructing Our Ships: Navigating the Use of Simulation in CSD," Teaching and Learning in Communication Sciences \& Disorders: Vol. 4: Iss. 3, Article 2.

DOI: https://doi.org/10.30707/TLCSD4.3/JNXD4642

Available at: https://ir.library.illinoisstate.edu/tlcsd/vol4/iss3/2

This Reflection on SoTL is brought to you for free and open access by ISU ReD: Research and eData. It has been accepted for inclusion in Teaching and Learning in Communication Sciences \& Disorders by an authorized editor of ISU ReD: Research and eData. For more information, please contact ISUReD@ilstu.edu. 


\title{
Reconstructing Our Ships: Navigating the Use of Simulation in CSD
}

\author{
Abstract \\ consequences. \\ Keywords \\ simulations, best practices, disruptive technology \\ Cover Page Footnote \\ NA
}

Simulations for clinical training is an example of a disruptive technology in that it offers great potential in the training and assessment of students and professionals in Communication Sciences and Disorders. As such, those considering adoption of simulations should anticipate the need for restructuring of the educational program in order to take full advantage of the benefits and minimize the unintended 
I was a doctoral student in 2000 when I first read an awkwardly titled article by Thomas Carroll, U.S. Department of Education, "If We Didn't Have the Schools We Have Today, Would We Create the Schools We Have Today?" (Carroll, 2000). In this article, Carroll described the history of the sailing industry in the early 1800's. During this time, sail ships reigned on both the seas and rivers. It was also during this time of the Industrial Revolution that steam power was transforming agriculture, manufacturing and transportation. With the invention of the steam engine, farmers were able to use machines to sow and reap harvests, laborers were able to harness steam for milling of wood, and steam locomotives traveled across the nation on transcontinental railways. Steam technology forever changed the face of this nation. It was not surprising that the sailing industry decided to adopt this new technology. Huge steam engines were placed on the decks of the wooden vessels, alongside the large masts and sails. The hulls of the ships were filled with heavy loads of coal to fuel the massive engines. It wasn't long before this approach to incorporating new technology proved flawed, and indeed fatal. There are many documented accounts of the ships catching fire from the ashes strewn from the smokestacks of the steam engines. According to Carroll (2000), the sailors preferred to continue with their old ways of sailing and had little tolerance for learning how to best harvest the power of steam. Despite the drawbacks, some saw the potential benefits of steam engines and went about transforming the sailing industry. This transformation required rebuilding the ships to accommodate the new technologies. Ships were soon built with steel and reconfigured to accommodate the massive engines. Carroll shared this story, as I share it with you, to illustrate that advancements in technology for teaching and learning will not reach their full potential without reconstructing the classrooms and programs in which they reside.

\section{Simulation as a Disruptive Technology}

Carroll argued that this new form of power and energy, the steam engine, was as a disruptive technology. According to Carroll, disruptive technologies benefit society in that they have the ability to "change our thinking about possibilities" (Carroll, 2000, p. 130) and become transformational tools. Simulation for clinical training is an example of a disruptive technology in that it offers great potential in the training and assessment of students and professionals. As such, those considering adoption of simulation should anticipate the need for restructuring of the educational program in order to take full advantage of the benefits and minimize the unintended consequences.

Simulation is described as a "technique that creates a situation or environment ...[sic] for the purpose of practice, learning, evaluation, testing, or to gain an understanding of systems or human actions" with a goal of increased patient safety (Lopreiato, 2016, p. 44). For purposes of this discussion, the term simulation is also applied to educational settings and need not pertain to medical scenarios. Simulation is an educational technique and/or tool for learning. A key premise of simulation, as in the application of any technology, is that learning does not reside in the technology. It resides in the educational design and practices. Simulations can be implemented as an assignment within academic coursework. They can be used as a method for obtaining clinical hours/competencies as part of a clinical education program. Additionally, simulation is applicable as a way of preparing students for a live clinical experience. Other programs employ simulations as part of intervention plans for struggling students. Anecdotally, there have been examples of when simulation has failed to meet its potential within our programs. Simulated learning 
experiences that are poorly designed and/or lack clear learning objectives or assessment measures, can leave students and instructors wondering about the benefits of simulation. Early in the advent of computer-based simulations, such as Simucase, instructors were likely to assign a simulation as an independent class assignment without proper instruction and/or follow-up. This resulted in confusion and frustration for both the learner and the instructor. Since that time, there has been a strong effort to education educators on the best-practices in simulation. Best-practices in simulation prescribe three distinct phases of simulation: the pre-brief, the simulation learning experience (SLE) and the debrief (The International Nursing Association for Clinical Simulation and Learning, 2019). It is argued that most learning occurs in the debriefing phase (Dieckmann, et al., 2009; Gaba, 2004; Jeffries, 2005). For a full description of best-practices including simulation design, facilitation, evaluation and assessment, the reader is referred to The International Nursing Association for Clinical Simulation and Learning (INACSL) website (https://www.inacsl.org/inacsl-standards-of-best-practice-simulation/) and other sources referenced in this article.

Our colleagues in nursing and medicine have a robust body of literature dating back many years establishing the benefits of simulation. Cook and colleagues (2011) conducted a meta-analysis of more than 600 studies across multiple disciplines. The results strongly support the use of simulation as an effective teaching tool. Research has consistently demonstrated that simulation can improve student performance and skills and positively impact confidence. Importantly, simulation training has improved patient safety (Alinier, et al., 2004; Cook et al., 2011). A landmark randomized control study in the field of nursing revealed that up to $50 \%$ of clinical education experiences can be replaced with simulation, and yield the same clinical outcomes (Hayden, et al., 2014).

There is also a rich and emerging body of literature pertaining to simulations in Communication Sciences and Disorders (CSD), as evidenced by this Special Topic Issue devoted to simulation research. Some of the earliest work on simulation in CSD was conducted by Syder (1996). Soon to follow was the work of Richard Zraick and colleagues (Zraick, 2002; 2004; Zraick, et al., 2003) regarding the use of standardized patients. With the increase in the amount and types of simulations employed in CSD programs (Dudding \& Nottingham, 2018) our colleagues have been busy conducting research on the topic. Those interested in a comprehensive resource for simulation in CSD are referred to the Council of Academic Programs in Communication Sciences and Disorders' (CAPCSD) e-book available online at the CAPCSD website (www.capcsd.org) (Dudding, et al., 2019).

\section{New Horizons in Higher Education}

Much like the large wooden sailing ships, programs in CSD have enjoyed a rich and open journey. That is, programs in CSD have been in high demand with acceptance rates of $65 \%$ and $71 \%$ for graduate programs in speech-language pathology and audiology, respectively (Council of Academic Programs in Communication Sciences and Disorders, 2019). The demand is likely to continue as the Bureau of Labor and Statistics cited audiology and speech-pathology as highly desirable professions with greater than average growth outlooks (Bureau of Labor Statistics, 2019, n.d.). In response, CSD has seen an expansion in the number of new graduate programs applying for accreditation from the Council of Academic Accreditation (CAA) of the American Speech 
Language Hearing Association (ASHA) (Council of Academic Accreditation, 2019). Along with high demand for professionals and an increase in the number of graduate programs, comes an increased burden on existing resources, including opportunities for student training across the scope of practice.

In 2016, ASHA's Council for Clinical Certification (CFCC) modified the implementation language for Speech - Language Pathology Standard V-B to allow up to 20\% of the required 375 direct clinical hours to be obtained through simulation (Council for Clinical Certification in Audiology and Speech-Language Pathology, 2013. With this change in language came the impetus for programs in CSD to adopt and/or expand the use of simulation for student training.

\section{Reconstructing Our Programs}

Recent world events, (i.e., COVID-19 pandemic), has caused the closing of university campuses across the nation. The universities have been forced to move academic coursework to an online format. Graduate training programs in CSD have been thrust full-speed into simulation as a way of providing clinical training for graduate students in audiology and speech-language pathology. With this disruption comes an opportunity to consider how we construct new learning environments, reimagine the curriculum, change how we view assessment, and revise our standards and policies to take full advantage of what simulation has to offer.

Reconstructing learning environments means more than putting rolling furniture and whiteboards into the classroom. Consider flexible design of spaces to accommodate small and large group work to include simulation and other specialty labs. Explore the possibility of sharing and/or "leasing" spaces from other programs. Offer extended learning opportunities and access to include weekends and evenings. Investigate various forms of technology, ranging in levels of fidelity from standardized patients, task trainers, manikins and virtual reality.

Moving beyond physical resources, it is essential that simulations are integrated into the curriculum. Simulation learning experiences need to be planned, scheduled, and implemented across the entire curriculum, with as many stakeholders involved as possible (Issenberg \& Scalese, 2008). The literature and experience have taught us that simulation-based learning is most effective when it is integrated with other learning tools. When used in conjunction with complementary means of clinical education, simulation learning experiences help prepare students in a safe, norisk environment prior to high stakes experiences with real clients or patients (Dudding et al., 2019).

Integration of simulations into the curriculum has the potential to move programs forward in how we assess students' knowledge and skills. Specifically, simulation can be used for formative assessment as well as summative high stakes evaluation of professional competencies. Several other healthcare professions, including medicine, utilize an objective structured clinical examination (OSCE) as a realistic and reliable method of assessing clinical competencies of entering professionals. In most cases, simulations are part of the OSCE experience. In addition to clinical skills, simulation allows for the assessment of professional skills such as interprofessional communication and teamwork. 
Lastly, fully embracing simulation in CSD will require changes in policy and procedures related to licensing and accreditation. Topics such as resource allocation, course credits, scheduling and the divisions between clinical and academic components need to be considered in an open and candid manner. As you read the articles presented in this Special Topic Issue of Teaching and Learning in Communication Sciences and Disorders (TLCSD) and other journals and presentations, you are encouraged to consider the findings in the broader context of the programs and how we educate future professionals. You are encouraged to take the lead in rebuilding your ships to take full advance of simulation as a valid and effective learning experience.

\section{Disclosures}

The author has no financial disclosures. Non-financial disclosure is that she serves as guest-editor for this special issue.

\section{References}

Alinier, G., Hunt, W. B., \& Gordon, R. (2004). Determining the value of simulation in nurse education: Study design and initial results. Nurse Education in Practice, 4(3), 200-207. https://doi.org/10.1016/S1471-5953(03)00066-0

Carroll, T. G. (2000). If we didn't have the schools we have today, would we create the schools we have today? Contemporary Issues in Technology and Teacher Education, 1(1), 117140. https://www.learntechlib.org/p/10807

Cook, D. A., Hatala, R., Brydges, R., Zendejas, B., Szostek, J. H., Wang, A. T., . . Hamstra, S. J. (2011). Technology-enhanced simulation for health professions education: A systematic review and meta-analysis. Jama, 306(9), 978-988. https://doi.org/ 10.1001/jama.2011.1234

Council of Academic Accreditation. (2019). CAA accredited program listing. https://caa.asha.org/wp-content/uploads/CAA-Accredited-Programs.pdf

Council of Academic Programs in Communication Sciences and Disorders. (2019). Communication sciences and disorders centralized application system applicant data report 2017-2018 https://wordpressstorageaccount.blob.core.windows.net/wpmedia/wp-content/uploads/sites/1023/2019/06/CSDCAS-Applicant-Data-Report-20172018.pdf

Council for Clinical Certification in Audiology and Speech-Language Pathology of the American Speech-Language-Hearing Association. (2013). 2014 Standards for the Certificate of Clinical Competence in Ppeech-Language Pathology. http://www.asha.org/Certification/2014-Speech-Language-Pathology-CertificationStandards/.

Dieckmann, P., Molin Friis, S., Lippert, A., \& Ostergaard, D. (2009). The art and science of debriefing in simulation: Ideal and practice. Medical Teacher, 31(7), 287. https://doi.org/ 10.1080/01421590902866218

Dudding, C. C., \& Nottingham, E. E. (2018). A national survey of simulation uses in university programs in communication sciences and disorders. American Journal of Speech-Language Pathology, 27(1), 71-81. https://doi.org/ 10.1044/2017_AJSLP-17-0015

Dudding, C. C., Brown, D., Estis, J. M., Szymanski, C., \& Zraick, R. (2019). Best practices in healthcare simulations in communication sciences and disorders. https://wordpressstorageaccount.blob.core.windows.net/wp-media/wpcontent/uploads/sites/1023/2019/06/eBook-Best-Practices-in-CSD-March-2019.pdf 
Gaba, D. M. (2004). The future vision of simulation in health care. Quality \& Safety in Health Care, 13 Suppl 1, 2. . https://doi.org/doi:13/suppl_1/i2 [pii]

Hayden, J. K., Smiley, R. A., Alexander, M., Kardong-Edgren, S., \& Jeffries, P. (2014). The NCSBN national simulation study: A longitudinal, randomized, controlled study replacing clinical hours with simulation in prelicensure nursing education. Journal of Nursing Regulation, 5, S1-S64.

Issenberg, S. B., \& Scalese, R. J. (2008). Simulation in healthcare education. Perspectives in Biological Medicine, 51(1), 31-46.

Jeffries, P. R. (2005). A framework for designing, implementing, and evaluating simulations used as teaching strategies in nursing. Nursing Education Perspectives, 26(2), 96-103.

Lopreiato, J. O. (2016). Healthcare simulation dictionary. Agency for healthcare research and quality, 16 (17), 96-103.

Syder, D. (1996). The use of simulated clients to develop the clinical skills of speech and language therapy students. European Journal of Disorders of Communication, 31(2), 181-192. https://doi.org/10.3109/13682829609042220

The INACSL Standards Committee. (2017). INASCL standards of best practice: Simulation SM: Operations. Clinical Simulation in Nursing, 13, 681-687. https://www.inacsl.org/inacslstandards-of-best-practice-simulation/

U.S. Bureau of Labor Statistics. Occupational outlook handbook: (n.d.) https://www.bls.gov/ooh/healthcare/speech-language-pathologists.htm

Zraick, R. (2002). The use of standardized patients in speech-language pathology. Perspectives on Issues in Higher Education, 5(1), 14-16. https://doi.org/10.1044/ihe5.1.14

Zraick, R. I. (2004). Playacting with a purpose: Using standardized patients to assess clinical skills. The ASHA Leader, https://leader.pubs.asha.org/doi/10.1044/leader.FTR5.09102004.22

Zraick, R. I., Allen, R. M., \& Johnson, S. B. (2003). The use of standardized patients to teach and test interpersonal and communication skills with students in speech-language pathology. Advances in Health Sciences Education: Theory and Practice, 8(3), 237-248. https://doi.org/10.1023/a:1026015430376 